\title{
Technology and Young Learners
}

\author{
Fidelis Chosa Kastuhandani \\ ELESP - Sanata Dharma University \\ chosakh@yahoo.com
}

\begin{abstract}
Nowadays, technology can be accessed by everyone easily, including young learners. This article discusses three things; the first is the discussion of what characteristics young learners have, the second discussion is about what kinds of technologies that could be integrated into classroom activities, and the third discussion is about how to weave ICT into young learners' classroom setting. Employing ICT in teaching English to young learners, indeed, provides challenges for teachers to overcome. By far, the most useful resources in the classroom are the students themselves.
\end{abstract}

Keywords: technology, young learner, ICT

\section{INTRODUCTION}

Younger learners are growing up with technology, and it is a natural and integrated part of their lives. For these learners the use of technology is a way to bring the outside world into the classroom. These learners are called digital native, a term that has been coined to refer to someone who grows up using technology, and who thus feels comfortable and confident with it.

Young learners, in this article, refer to children from the first year of formal schooling (five to six years old) to eleven or twelve years of age. These early years of schooling are a time of rapid physical, social, emotional and intellectual growth. As children progress through these early years they gain more independence as learners and benefit from learning strategies that meet their individual needs. They develop a broader range of social skills and become more aware of the world in which they live. These young learners, more than ever before, engage with information and communication technologies as powerful learning tools within and outside their classrooms. They are interested in and quickly become adept at applying new technologies.

This article is divided into three parts. The first is the discussion of what characteristics young learners have. These characteristics are important since by understanding the characteristics of the learners, teachers could choose the kind of technologies $s /$ he could use to support the teaching-learning processes. The second discussion is about what kinds of technologies that could be integrated into classroom activities. However, since the term "technology" covers all the things ranging from blackboard to World Wide Web (Dudeney \& Hockly, 2007) in this article I will limit the discussion on the use of Information and Communications Technology (ICT) in classroom settings. The third discussion is about how to weave ICT into young learners' classroom setting. Here, I would like to share the ideas of using ICT in teaching listening, speaking, reading, and writing to young learners.

\section{YOUNG LEARNERS' CHARACTERISTICS}

The way children learn a foreign language, and therefore the way to teach it, obviously depends on their developmental stage (Phillips, 2003). Caregivers and teachers should be able to provide developmentally appropriate instruction. They must be aware of children's basic physical and psychological needs. Brazelton and Greenspan (2000) as cited in Linse (2005) propose that such awareness is needed since children require and deserve professionals who interact with them 
in appropriate ways based on the child's social/emotional, physical, cognitive, and moral development.

By being aware of what children can and can't do developmentally, teachers are better able to provide appropriate learning experiences for their young learners. Observing the child's development enables teachers to provide the young learners tasks which are within their reach, tasks where they will succeed and experience success. This success, furthermore, gives them the confidence to attempt tasks which are progressively more difficult.

The younger the learners are, according to Phillips (2003), the more holistic learners they will be. Younger learners respond to language according to what it does or what they can do with it, rather than treating it as an intellectual game or abstract system. Further, younger learners have the advantage of being great mimics, are often unselfconscious, and are usually prepared to enjoy the activities the teacher has prepared for them. However, there are some points a teacher should consider:

1. The activities should be simple enough for the children to understand what is expected of them.

2. The task should be within their abilities: it needs to be achievable but at the same time sufficiently stimulating for them to feel satisfied with their work.

3. The activities should be largely orally based.

4. Written activities should be used sparingly with younger children. Children of six or seven years old are often not yet proficient in the mechanics of writing in their own language.

Furthermore, Linse (2005: 4-5) in her book, citing McClellan and Katz (2001), mentions several attributes of children's development. To mention some, emotionally and socially, a child is usually in a positive mood; is not excessively dependent on adults; enters ongoing discussion; and shows interest in others. The attributes of cognitive development include can follow instructions; understands the concept of symbols such as numbers and letters; is interested in academic content; likes reading or being read to; likes playing with words, numbers, or abstract symbols; and can follow a sequence of events. Furthermore, physically a child can demonstrate muscle control and coordination to do certain activities.

Therefore, by recognizing the characteristics of young learners, a teacher should make adjustments on what technologies will help her/him in achieving the goal of learning processes. Further consideration on the appropriate development of children could also provide her/him specific information on the physical and psychological needs of the learners to gain the best possible result of learning.

\section{ICTS FOR CLASSROOM USE}

The use of ICT to support young learners is becoming increasingly common place in the mainstream and specialist classroom. The value of using ICT is considerable and works on a variety of levels to support both teaching and learning. The motivational aspect of ICT is clear. Learners who are very new to learning a new language find activities on the computer that they can do instantly. Also they feel that here is something that they can do, and often as well as, if not better than, their peers.

Creative use of ICT in the classroom can promote inclusion and reflect cultural and linguistic diversity. Learners who have had very little experience of using ICT can engage in exciting activities that are accessible with even very limited English language knowledge. Similarly ICT literate pupils can explore ICT based activities that are not dependent on an equivalent level of fluency in English. Learners can present and share their work which has positive motivational effects and raises selfesteem.

The use of multimedia in presenting information is an important way of supporting access for the learner. ICT gives us the means to add pictures, sound and video, to use key visuals and graphic organizers, and to use the wealth of content rich sources from a range of 
cultures, that can be found on the internet. The use of word processing technology opens up an infinite range of opportunities. The combination of spoken, written, visual and picture support gives the learner the scope to engage in meaningful curriculum focused activities at a linguistic level that is matched to their level of English language development. However, the challenge is to know which software and hardware is available.

There are a lot of ICT tools that can be used to enhance the teaching and learning process in classroom settings. However, in this article I focus on four ICT tools mostly available everywhere. The tools are word processor, presentation tool, the Internet, and technology-based courseware.

\section{Word Processor}

Word processor can be used in many inventive ways, by both teachers and students. Teachers can prepare, create, store, and share materials for their classes by using a word processing program, and learners can use a word processing program both in and outside the classroom, to practice writing skills, grammar and other language points, as well as to present their work.

There are various kinds of possibilities that can be achieved by exploiting word processors to meet the needs of learning objectives for encouraging young learners to practice using the language. The first possibility of using word processors is for creative writing. Learners can work together with documents that can be exchanged easily between pairs or groups of learners, and between learners and teachers, encouraging both teacher corrections, and peer correction and revision.

However, there is a consideration regarding the use of word processors with young learners. Young learners might have different levels of typing skills. This difference could play a large part in performance anxiety and in the pace at which activities are carried out. Teachers, therefore, should pay attention not putting too much pressure on the learners to perform too quickly.

Starting with simple activities and getting the learners used to the mechanics of word processing before moving on to the more creative side will be a good grounding in the writing process.

\section{Presentation Tool}

Presentation tool also can be used in many ways. The accessibility of this presentation program to include sound, animation, video, and text provides various possibilities for both teachers and students to exploit. Teachers can also prepare, create, store, and present animated materials for their classes, and learners can use the program to practice various kinds of language exercises and to present their group work project, for example, to the whole class interestingly with the help of projectors.

The possibilities to add sound, video, animation and text in presentation slides bring about possibilities for teachers to make animated materials for in and outside classroom activities. In class, teachers could use projector to present the material for the whole class to see and even teachers could also make an audio story so that learners can read and listen to the story outside the classrooms.

\section{The Internet}

There is a large and constantly expanding collection of resources on the web, at a variety of levels and covering an amazing array of topics. The web is a source of content which can be used as a window on the wider world outside the class and a readily available collection of authentic material.

However, using the Internet in the language classroom has many other tangible benefits. The multimedia possibilities allow teachers to introduce content in diverse ways and thus appeal to the learning styles or 'intelligences' of more children (Lewis, 2004). Further, he also proposes that the Internet is also highly motivating. Information on the Internet is enormously diverse and not organized in any linear way. It can be used to encourage independent learning and creative thinking skills, as children can make more decisions about how to approach the information. 
However, Dudeney and Hockly (2007) mention that teachers of young learners with low levels of language proficiency should consider the choice of websites that will provide the learners with understandable language and contexts. Choosing the right websites can go some way towards raising the learners comfort levels. Websites which are more suitable for lower levels will include:

- Websites with simple, clearly presented texts.

- Websites with non-linguistic data which is easy to interpret.

- Websites with visuals.

- ELT websites, where the content has been written, edited and prepared with this audience in mind. (Dudeney and Hockly, 2007)

Besides websites, the Internet also provides other facilities that can be exploited for language learning purposes. The first is search engines; the tool is almost directly analogous to a telephone directory, or any other database of stored information. People search for a name or a title, and the directory gives them more information about the entry. The second tool is email. Email is one of the most used and useful ICT tools today. Email allows teachers to communicate with learners outside the classroom, for example setting, receiving, marking and returning homework and other written assignments. By using email, learners can do keypal projects - email projects set up between learners in different classes or countries. The third tool is chat. Chat has the potential to link students around the world, in real time. It is a technology that many learners will often be familiar with and will use in their social lives. And the last one being discussed here is blogs. A blog is essentially a web page with regular diary or journal entries. It allows learners to connect, to communicate, and to collaborate online.

\section{Technology-Based Courseware}

Often, a course book is accompanied by a CD-ROM. A CD-ROM is a CD that contains multimedia files that are programmed to use text, images, audio and video to provide interactivity. CD-ROMs accompanying courses typically have content related to each course unit, providing young learners with extra reading and listening materials, recording functionality to practice pronunciation and speaking, and with grammar and vocabulary activities like matching vocabulary to definitions, drag and drop exercises, gap-fills, crosswords, and so on.

\section{WEAVING ICT INTO CLASSROOM SETTING}

In this section, I will discuss the possibilities of weaving the aforementioned technologies in young learners' classroom setting. I will divide this section into four, in accordance with the language skills being covered: listening, speaking, reading, and writing. Further, I also would like to share some ideas on how to use technology in supporting the teaching process of those skills.

Considering the learning channels the young learners have - auditory, tactile, and visual - teachers should try to present information using all three learning channels. Fortunately, presenting materials incorporating all those learning channel is possible by using the technology in an effort of supporting teaching and learning process.

\section{Listening}

Young children listen to a variety of voices and sounds that are around them. Linse (2005) proposes that the relationship between listening and speaking is clear because they are both oral skills. By listening, children are preparing to replicate the sounds when they speak. In addition, there are specific listening skills which can lay the foundation for reading instruction because by developing good listening skills, children are able to match the sounds with the corresponding symbols when they decode words.

There are many classroom techniques and activities that can be done in improving the learners' listening skill. There are TPR activities, TPR songs and finger-plays, TPR storytelling, TPR drawing, syllable clapping, rhyming word activities, and minimal pairs (Linse, 2005).

Here, teachers could use presentation tool to teach, for example, minimal pairs. 
Minimal pairs are two words that differ in only one sound. For example, ship and sheep are minimal pairs. One way to practice minimal pair distinction is to have the learners listen to two words and tell whether they are the same or different. In order to make it more meaningful, pictures can be used. Teachers create two presentation slides for the minimal pairs. One slide is for ship and the other is for

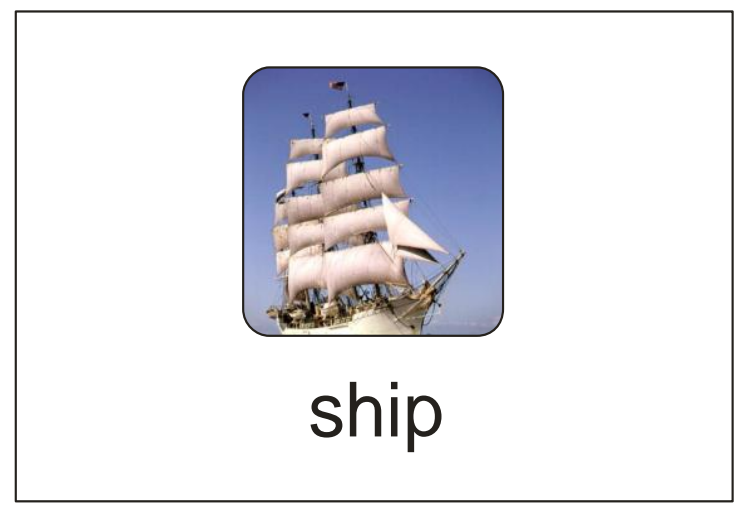

Speaking

Speaking activities are an important part of any young learners' classroom and are often considered the focal point of instruction. When teaching speaking, it is important to choose activities which match the objective of the course.

There are several techniques and activities that can be done in a speaking class. They are Audio-lingual Method, dialogues, using puppets to introduce dialogues, fishbowl technique, Communicative Language Teaching, games, talking and writing box, teaching pronunciation, and error correction (Linse, 2005).

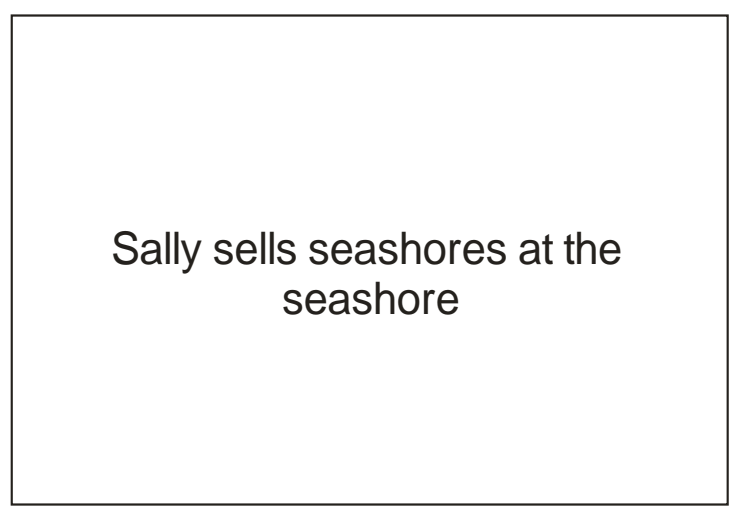

sheep. An audio file, further, can be attached in the slide in order that when the learner clicks the mouse, the pronunciation is heard. If the learner clicks the mouse the second time, the next slide will appear showing an image of sheep and the pronunciation of the word. Using images and sound in the practice of minimal pairs could bring the word more meaningful for the learners.

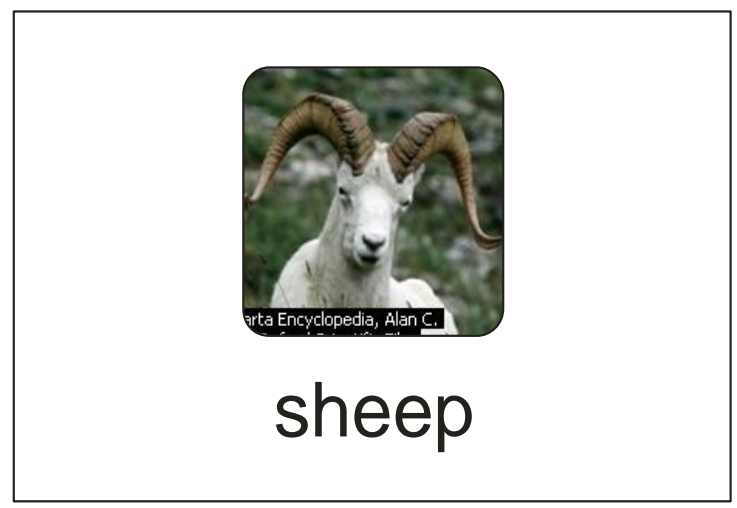

In order to be able to teach pronunciation to learners aged 6 years of age, a teacher could use presentation tool to create the material. Here, teachers could use tongue twisters to teach pronunciation to children learning English as a second or foreign language. For example, the teacher chooses Sally sells seashells at the seashore and Peter Piper picked a peck of pickled peppers. If Peter Piper picked a peck of pickled peppers, where's the peck of pickled peppers that Peter Piper picked? Children will adore tongue twisters because they perceive saying the sounds as a game or a challenge.

Peter Piper picked a peck of pickled peppers. If Peter Piper picked a peck of pickled peppers, where's the peck of pickled peppers that Peter Piper picked? 
The example above consists of two presentation slides. When the first slide appears, the learners should practice the tongue twister until they can pronounce the sentence fluently. Further, after the learners succeeded to master the first slide, the learners could simply click to open the next slide. To make it more meaningful and provide correct pronunciation of the sentence, teachers could also add audio file to the slides. The Internet also provides numerous tongue twisters that are available.

\section{Reading}

Reading comprehension refers to reading for meaning, understanding, and entertainment. It involves higher-order thinking skills and is much more complex than merely decoding specific words. Teaching children how to derive meaning as well as analyze and synthesize what they have read is an essential part of the reading process.

Teaching children to read requires children's ability to read in their own language. If children can read in their own language already, even if it is written in a different script, teaching them to read in English would not be as difficult if they cannot read even in their

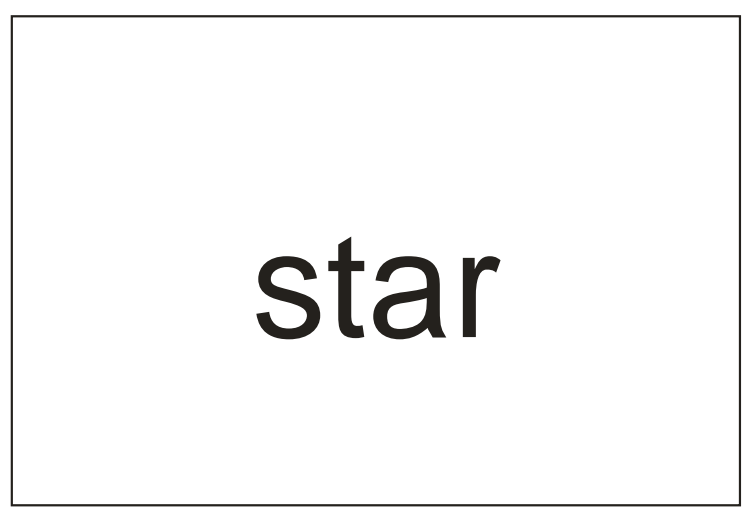

To play the game, the teacher opens the presentation slide so that the children can see the word on the slide and mentions all the words on the slides. The children have to look at the slides and listen carefully to the teacher's words. When a certain slide appears, the children repeat the word that is on the card when they hear it mentioned by the teacher. own language. However, the teaching situation is the most important factor when deciding how teachers should teach reading.

There are two main approaches to teaching reading in English according to Slattery and Willis (2001). The first is look and say. Teachers often use 'look and say' as part of vocabulary teaching. So when children learn to say a new word they learn to read it. Teachers can help children with whole word recognition by using printed material as much as they can in the classroom. The second approach is phonics. Children need to recognize sounds and letters. It is better not to teach the names of letters when starting to teach reading, as some of the letters of the English alphabet no longer match the actual sounds of the language. When teachers use phonics, they are teaching children the way the letter sounds, not the name of the letter.

Integrating technology into teaching reading to children can be done by letting the students play a game called 'clever parrot'. The children have to repeat like a parrot. But they must be clever parrots and only repeat the word on the card. The teacher's job is making a presentation slides with certain word on each slide.

\section{moon}

The other idea about using technology in reading class is playing label game. Here, the teacher creates a document which has forms in it by using a word processor. The teacher inserts a picture on the document and makes forms on every object in the picture. The idea is that during the game, the children can type in the name of the object in the forms and finish if there is someone who has finished 
completing the picture. Then, the teacher could check whether the children have input the correct name for each object.

\section{Writing}

Like the other three language skills, writing is about meaning. Early writing activities such as copying, tracing, and making letter shapes are handwriting practice. Finding the letters for computer work is a matter of recognition and developing keyboard skills. However, children always have to think about the meaning of what they are writing. And whatever the lesson focus on - handwriting practice or keyboard skills or expressing meaning or a combination - children should enjoy the activity and feel successful.

To make the children recognize and develop their keyboard skills, a teacher could employ a word processor to teach them writing. The children could copy/type from memory the word/phrase that matches the picture, write a label, finish the word, type the whole word, copy/type the names of all the people in the story, copy/type the story in the right order, copy the phrase/sentence putting in the missing word, or have writing race game.

The idea of integrating technology in writing class is by using process writing approach. There are five steps done in process writing. The first step is prewrite. Children are given an opportunity to prepare to write and to collect their thoughts and ideas. The second step is write. The children are writing down all of their ideas. They do not worry about form or corrections or even the order. The objective is to get the ideas on paper as quickly as possible. The next step is revise. The initial piece of writing is examined and reworked so that the ideas are logical and flow together. The fourth step is edit. The children (with the help of their teachers or classmates) proofread their work to make sure that there are not any content errors or grammatical or spelling errors. Meanwhile, the last step is publish. The writing piece is rewritten in a published or presentable form, on a computer so that it can be displayed or shared. Furthermore, the children could post their writing in their own blogs or the class blog so that everybody, including the parents, could read their piece of writing.

Another idea on integrating ICT into writing class is grounded on the fact that children love to find out about other children. Lots of children around the world are learning English. So the children could write to other children anywhere in the world, not just to children whose mother tongue is English. Writing to penpals is actually a very practical way to use English and it lets children see the real value of learning another language - to communicate and find out about other people. When children do this they are learning about other attitudes and ways of doing things. They are not just practicing their English; they are opening their minds to the rest of the world. This writing can be done by using email and chat function of the Internet. However, here the teachers' role is to observe and guide the children so that they are not writing to the wrong person. Teachers should make sure they know who the children are writing to. If children become aware that English can be used to talk to or write to people in different countries, they will begin to understand why they are learning this new language.

\section{CONCLUSION}

Employing ICT in teaching English to young learners, indeed, provides challenges for teachers to overcome. However, by far, the most useful resources in the classroom are the students themselves. Through their thoughts and experiences they bring the outside world into the room, and this is a powerful resource for teachers to draw on.

Although without using any educational technology teachers can still survive and students can get various language experiences, educational technology will provide the tools to enhance the teaching learning process. The integration of technology into teaching learning process requires only 
teachers' creativity to employ technology to support their efforts. Furthermore, computers and the Internet are not replacements for classroom teaching as we can see from the discussions above. Many people believe that the technology can 'do' things to help the language learning process. In fact, technology can do nothing. Only when the technology is combined with offline activities does it reach its enriching potential.

\section{REFERENCES}

Dudeney, Gavid \& Nicky Hockly. (2007). How to teach English with technology. Essex: Pearson Education Limited.

Dudeney, Gavin. (2005). The Internet and the language classroom: A practical guide for teachers. Cambridge: Cambridge University Press.

Harmer, Jeremy. (2007). The practice of English language teaching. $4^{\text {th }}$ ed. Essex: Pearson Education Limited.

Lewis, Gordon. (2004). The Internet and young learners. Oxford: Oxford University Press.

Linse, Caroline T. (2005). Practical English language teaching: Young learners. New York: McGraw-Hill ESL/ELT.

Phillips, Sarah. (2003). Young Learners. Oxford: Oxford University Press.

Shrum, Judith L. \& Eileen W. Glisan. (2005). Teacher's handbook: Contextualized language instruction. $3^{\text {rd }}$ ed. Boston: Thomson Higher Education.

Slattery, Mary \& Jane Willis. (2001). English for primary teachers: A handbook of activities \& classroom language. Oxford: Oxford University Press. 